\title{
Emerging explosives and initiation devices for increased safety, reliability and performance for excavation in weak rocks, mining and close to surface structures
}

\author{
RN Gupta \\ Former Director at National Institute of Rock Mechanics \\ Kolar Gold Fields, India \\ guptarn1942@gmail.com
}

\begin{abstract}
Rock breaking, rock excavation, concrete breaking, foundation rock breaking, trenching, tunnel widening in sensitive environments such as close to high rise buildings, schools, hospitals, roads, electrical installations, existing and operative dam foundations, piers, pipeline laying below ground, indoors and secondary breaking of large rock boulders in quarries, are growing burning problem in most of the coal and other mines, big cities and metros. Uses of Drilling and Blasting with conventional explosives for rock breaking in such cases are either prohibitive because of the act, rules and regulations of the country's laws or not feasible due to local problems since even a controlled blasting technique causes vibrations, fly rock and noise beyond the permissible limits.In all such cases one of the big limitations is excavation output to meet the construction timetable.The rapidly growing civil excavation and infrastructure in India for sensitive rock breaking is estimated at about 5 million $\mathrm{m} 3$ per annum. The NoneX rock breaking method, developed by NXCO Mining Technologies, has been extensively used in several applications in wide Varity of rock conditions. The NoneX technology allows a tailored rock breaking (TRB) approach whereby energy can be applied more efficiently to break and dislodge the rock in a controlled fashion, which can be optimally adapted to suit the rock breaking requirements of any particular situation in all types of rock conditions. NoneX cartridges with inbuilt detonators will not pose problems as the detonators contain explosives (similar to PETN powder) are also classified under Division 1.4S Chemicals by UN and classified as class-6/7 blasting caps explosive as per Indian explosive regulations, 1983/reaffirmed in 2005.
\end{abstract}

The advantages of non-detonating Pyrotechnic system of rock breakage in open pit mining and civil construction sites greatly reduced the "danger Zone" to $30 \mathrm{~m}$ from $250 \mathrm{~m}$ with the conventional blasting because with this system the energy required to break a unit volume of rock mass was $1 / 10$ of the energy required with the conventional blasting using high explosives. The lower use of energy resulted in significant reduction in fly rock, air blast and blast induced ground vibrations. In addition the over breaks were greatly reduced resulting in reduction of damage and supports to the rock mass. As a result of reduced evacuation distance of 20 to $30 \mathrm{~m}$ for personnel and equipment's the restrictions for continuous operation and excavation near the power lines, pipe lines and high rise buildings also significantly reduced thereby increasing the overall productivity.

It is anticipated that the efficient use of non-explosive rock breaking techniques will make the concept of "Underground Space Technology" a more viable option in our cities where underground space will demand a premium in short term future. Underground space is an increasing popular option for car parks, and storage places in several highly urbanized areas and these non-explosive methods are one of the most applicable methods to use for excavation in most of the developing and developed countries where more and more stringent laws and regulations are being enforced with regards to disturbance.

Keywords-non-detonating pyrotechnic controlled blasting; danger zone; Pulse plasma

composition;

\section{I.INTRODUCTION}

Present trend world over in mining is bigger and bigger sizes of surface mines with bigger and bigger earth moving machines involving large amount of explosives coupled with sprawl of urbanization and increased public environmental consciousness. Large amounts of mineral reserves are locked-up in the lease areas of several mines in India because of the unplanned growth of rural and urban populations over years around mining areas. Many infrastructure projects are suffering in terms of time and cost overruns because of public protests and greater environmental consciousness. These have called for much greater control over blast induced ground vibrations, noise and fly rocks in the vicinity of habitation like construction of metro stations, tunnels, airports etc. by way of identifying a system of blasting which can give desired results in the most economical way without damaging nearby structures and raising noise and flyrock. For evolving newer and safer explosives and initiation systems it is necessary to clearly understand the recent advances in dynamics of rock breakage. For increasing production and productivity the mine operators and infrastructure companies are to adopt latest technology available globally. Therefore, R\&D efforts should be directed in India for the newer generation of safe non detonating explosives/pyrotechnic compositions and initiation systems. 
The issue of fly rock and blast damages in rock excavations and poor rock mass conditions has a large impact on the development of escalating number of products on the market claiming to reduce the effects of noise, vibration, dust and flyrock, as well as other advantages including preserving the rock mass strength and reducing the dilution in the mined ores.. The present methods of 'controlled blasting' predominantly in use in India within $250 \mathrm{~m}$ from any structure consist of restricting the charge per delay and 'muffling' the area of blasting. These measures are inadequate and do not yield desired results leading to several litigations, agitation by the public and stoppage of blasting. In several coal and non-coal mines blasting within say $100 \mathrm{~m}$ of any structure is by and large prohibited by DGMS. In addition, even when blasting is done within say $250 \mathrm{~m}$ from any structure not belonging to the owner (mine) DGMS imposes restrictions in terms of vibration, fly rock, and sound. Blasting within $250 \mathrm{~m}$ is done after taking permission from the DGMS to conduct low intensity trial blasts to record the ground induced vibrations, sound and distance of flying fragments. Based on trial blasts (say minimum 10 blast recordings) a site specific propagation equation relating blast induced ground vibrations in terms of peak particle velocity (PPV/Vppv $\mathrm{mm} / \mathrm{s}$ ) with maximum quantity of explosive per delay (Qm $=\mathrm{MCD}$ ), and the distance (D) of the structure from the blasting site is established using simple regression analysis. The most accepted equation takes the form of

$\mathrm{Vppv}=\mathrm{k}(\mathrm{D} / \mathrm{Qm})-\beta$, where $\mathrm{k}$ and $\beta$ are the rock and explosive constants respectively for a specific site and therefore, shouldn't be used at other sites. To contain the flyrock, the most commonly used technique is "muffling" which consists of putting sand bags over the blast holes and then covering the blast holes by wire mesh or by rejected belt conveyor pieces again followed by sand bags. This method is partially effective in containing fly rock. Use of "Blasting Mats" consisting of several old tyres stitched together in a wire rope strand although is effective butis not usedby mining industry becauseof cost factor.In most of mines and infrastructure projects where blasting with conventional explosives is done within $250 \mathrm{~m}$ of any structure result in several litigations and agitationsby public leading to work stoppage. It is appropriate to mention that the so called "controlled blasting" is not implemented in true spirit and therefore, not found to be effective. It should be remembered that one bad blast out of several good blasts is enough to stop the project.

It has been established by researchers (see Hoek's damage factor/ and Verma, H; 2014) that with conventional blasting the rock mass around tunnels and high wall side of rock benches are damaged up to $3 \mathrm{~m}$ underground tunnels/caverns/ roadways; and up to $6 \mathrm{~m}$ in surface mines, from the excavated perimeters. As a result the damaged rockzone in underground structures is supported using rock bolts, shotcrete, ribs, and or concrete lining. If this damaged zone is reduced then tunnels/slopes supports canalso be significantly reduced.Similarly, in thin vein ore mining a lot of dilution occurs from the hanging wall sides thus reducing its sell price.
This paper describes the development and application of pyrotechnic compositions similar to propellant, also termed as "Non-detonating explosives",and also Plasma Blasting for non-destructive rock excavations. The pyrotechnic composition is basically consisting of Ammonium Nitrate and Nitro Cellulose which on initiation by a detonator produce only gases, at a VOD (velocity of detonation) below $1000 \mathrm{~m} / \mathrm{s}$, resulting in very low levels of ground vibrations, no fly rock and little sound. In the beginning of this century it was tried on a small scale in South Africa but currently it is experiencing a boom in many countries including China, Australia, South Africa, Mexico, United Kingdom, Spain, and Sweden and recently in Canada.The Petroleum \& Explosive Safety Organization (PESO) of the Govt. of India, has permitted its import to India vide letter No. E25(33)MISC/06 dated 21/09/2007, Nagpur. However, in India it was demonstrated at a trial stage in one of the Hydro Power Project but yet to be experimented on a commercial scale. The non-explosive or non-detonating propellant mixtures are enclosed in plastic cartridges and are classified all over the world as a Division 1.4 Compatibility Group S Chemicals by UN and also as per European Council Directive 93/15/EEC of 5th April, 1993) similar to Propellant which are not explosives. As per Indian Explosive Rules 1983, amended in 2005 these pyrotechnic compositions/ propellant are under class- 6 ammunition, and class-7 firework. A few of such products trade named including NoneXTM (South Africa, China, and Australia), ROYEX (by AB Etken Technoloi, Runsatravagen, Farsta, Sweden), PYROBLAST (Mexico/Spain), AUTOSTEM (South Africa) are available in the world market. All the mentioned products are certified to comply the UN Classification of Hazardous Substances as a Division 1.4S and are being widely used in circumstances where conventional detonating type of explosives are not permitted.

In the beginning of this century Korea Accelerator and Plasma Research (KAPRA) developed "Pulse Plasma Rock Fragmentation Technology"/ Electro Power Impact (EPI) for near populated areas and in weak rock mass as a safe and economical replacement to conventional explosives [2]. In EPI system, high power pulse electric energy generated is supplied through embedded electrodes to the cells filled with powders of Aluminium and copper oxide in milliseconds. As a result the cells electrolyte converts to plasma state, and generates high heat and impact wave (pulse), fragmenting the rock with weak noise and vibration. The system is good but the cost of breakage is high and therefore, is not popular.

There are several cases on record of tunnels and caverns collapses in many Projects in India and major slides of rock slopes along highways and at portals of tunnels. Most of the recorded collapses and slides were attributed to uncontrolled blasting using the conventional explosives during construction [3]. In all such cases great advantages could have beenaccruedin terms of stability of rock structure by retaining the integrity of rock mass resulting in saving in support cost by using non-detonating pyrotechnic compositions for non-destructive blasting. The 
rapidlygrowing civil excavationand infrastructure in India for sensitive rock breaking is estimated at about 5 million $\mathrm{m} 3$ per annum with trends moving towards denser populated cities with its stringent rock breaking constraints, higher environmental standards, reduced tolerance to the effects of conventional blasting, and increased security aimed at limiting the availability of high explosives in civil areas. In all such cases the use of non-detonating pyrotechnic compositions can meet the dual objective of structure's stability and safety in rock breaking with reasonable economy. In South Africa the non-detonating explosives are used for breaking over 120 million $\mathrm{m} 3$ of narrow vein minerals (mainly for gold mining to reduce dilution in the extracted ore)[1].

\section{II.NON-DETONATING EXPLOSIVE/PYROTECHNIC COMPOSITION- TYPES}

All such pyrotechnic compositions are certified to comply the UN Classification of Hazardous Substances as a Division $1.4 \mathrm{~S}$ and are being widely used in circumstances where conventional detonating explosives are not permitted. The UN Classification of Hazardous Substances Division $1.4 \mathrm{~S}$ is defined as:

"Articles and substances that present no significant hazard. This division comprises articles and substances, which present only a small hazard in the event of ignition or initiation during transport. The effects are largely confined to the package and no projection of fragments of appreciable size or range is to be expected".

Articles and substances in this Division are placed in Compatibility Group S when they are so packaged or designed that any hazardous effects arising from accidental ignition are confined within the package unless the package has been degraded by fire, in which case all blast or projection effects are limited to the extent that they do not significantly hinder fire fighting or otheremergency response efforts in the immediate vicinity of the package and that the product is incapable of an explosion whilst in its packaged state even if it is accidentally ignited or otherwise initiated by external means.

The non-detonating pyrotechnic compositions for rock breakage that have been around for many years and which are now in the forefront of the market included:

i) Pyrotechnic compositionssimilar to propellants and fire arms but are not explosives. These are maximum used for non-destructive rock breaking for ex. NoNex, Royex, Pyroblast and Autostem which are themost economical method of rock breakage after explosives,

ii) CARDOX (classified as non-explosive high pressure $\mathrm{CO} 2$ gas generator- used in British and Indian coal mines upto end of 50's until Permitted Explosives were invented.

iii) Penetrating Cone Fracture (PCF) - mainly used for splitting the boulders and fracturing rock mass insitunot popular due to limitations

iv) Pulse Plasma Rock Fragmentation method/

v) Electro Power Impact (EPI) - mainly used in South Korea and to a lesser extent in few other countries including Japan.
The first one i.e. non-detonating pyrotechnic compositions are at present widely used world over in situations including where minimal blast induced vibrations, flyrock and sound are permissible including heritage buildings, digging of foundations in rocks around multi storied buildings in populated areas, boulders breaking, ore mining in poor rock mass and narrow veins, metro stations, and where old RCC structures are to be demolished.

The main advantage of using above mentioned types of non-detonating explosives/Pyrotechnic compositions includes:

a) The man and machines are required to be moved away from the blasting sites to a maximum distance of 20-30 $\mathrm{m}$ for their safety,

b) Blasting can be done at any time $24 / 7$,

c) The non-detonating explosives can be imported without any restrictions as per the permission granted by the PESO of GOI,

d) They need not to be stored in explosive magazines,

e) They can be transported in any vehicle without any restrictions,

f) In tunneling the supports required to contain the tunnel deformations are minimum.

\section{III.COMPOSITION, PROPERTIES, MERITS/ DEMERITS \& USE OF} NON-DETONATING PYROTECHNIC COMPOSITIONS

The non-detonating pyrotechnic compositions composed of a mixture of Ammonium Nitrate (NHNO3), Nitrocellulose as propellant, and Dibuthylphthalate (3-6\%), including some other 10 chemicals. Its specific gravity is approx. 0.9. They are available in Plastic tube of various lengths 75 to $460 \mathrm{~mm}$ and external diameter 12, 13, 28, 34, and $60 \mathrm{~mm}$.

Each Cartridge contains 20 to 500 grams of a $50 / 50$ nitrocellulose propellant and ammonium nitrate mixture. For ex. NoneXTM cartridges come in a range of diameters and charge weights:

TABle I: NoneX ${ }^{\mathrm{TM}}$ CARTRIDGe Sizes (With Inbuilt Detonator OR STANDALONE STATE)

\begin{tabular}{|c|c|c|}
\hline $\begin{array}{c}\text { Cartridge dia. } \\
(\mathrm{mm})\end{array}$ & Hole diameter (mm) & $\begin{array}{c}\text { NoneX charge } \\
\text { Weight }(\mathrm{g})\end{array}$ \\
\hline 28 & 30 to $34 \mathrm{~mm}$ & 20 to $120 \mathrm{~g}$ \\
\hline 34 & 36 to $42 \mathrm{~mm}$ & 20 to $180 \mathrm{~g}$ \\
\hline 60 & 64 to $76 \mathrm{~mm}$ & $200-600 \mathrm{~g}$ \\
\hline
\end{tabular}

NoneX cartridges come in a range of diameters and charge weights as detailed in Table-I above.

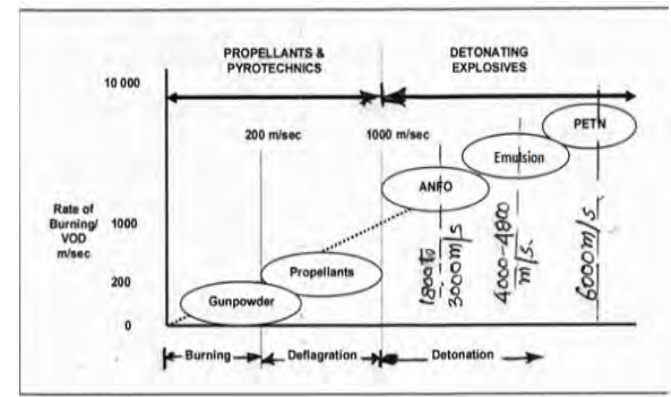

Fig.1 illustrates the rate of burning, deflagration, \& detonation of gunpowder, propellant, \& explosives respectively. 


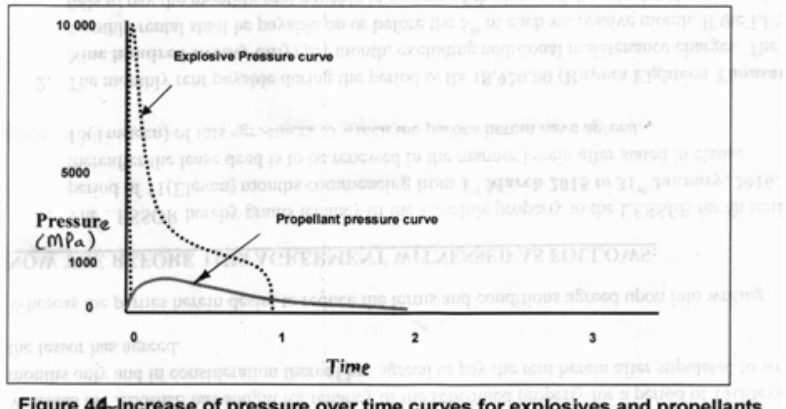

Figure 44-Increase of pressure over time curves for explosives and propellants confined in a drill hole in rock

Fig.2 illustrates the attenuation of borehole pressure for explosives and non-detonating explosives /pyrotechnic compositions/ propellants

Another non-detonating explosive in the market is "Royex" from Sweden, with built in detonator, containing explosives similar to PETN, (classified as UN 1.4S compatibility and class-6 blasting cap as per Indian Explosive. Regulation, 2005). Royex cartridges are certified under European Safety Standards (CE). Since the Royex cartridge propellant is designed to deflagrate rather than to explode, the gas volume expansion is rapid but slow when compared to detonation of explosives (see Fig.2). The gas expansion generates a pressure wave in the surrounding rock. The energy of this pressure wave attenuates as the distance from the blast hole increases. The rate of attenuation depends on the quantity of explosive detonated per delay, distance of the object from the blast site and the rock mass parameters. Generally, with non-detonating pyrotechnic compositions the ground frequencies are +400 $\mathrm{Hz}$ and therefore, the structures can sustain higher ppv when compared to conventional frequencies below $50 \mathrm{~Hz}$ recorded with conventional explosives. Thus, it is possible to use higher maximum charge per delay (MCD) with pyrotechnic compositions. It is appropriate to mention that the initiation systems for non-explosive compositions are identical to that of explosives. Thus, for small blasts (max. of 20 holes) one can use electric short or long delay detonators and if the blast size is greater than 20 holes but below 100 holes then "sequential blasting machine" may be used up to about max. of 90 holes in a round of blast. Preferably, NONEL system with shock-tube should be used for larger number of holes per round. The non-detonating explosivetechnology allows a tailored rock breaking (TRB) approach whereby energy can be applied more efficiently to break and dislodge the rock in a controlled fashion, which can be optimally adapted to suit the rock breaking requirements of any particular situation in all types of rock conditions.

\section{A. Advantages of Non- Explosive RockBreaking} pyrotechnic Compositions overConventional detonating explosives

1) Environment friendly

a) Minimal Fly rock $(<10 \mathrm{~m})$ but can be eliminated with "muffling of blast area

b) No shattering /damage of rock mass due to shock waves but only heaving due to gas release.

c) Minimal blast induced ground vibrations because of low charge factor as compared to conventional explosive.
With NoneX the charge factor is $0.10-0.15 \mathrm{~kg} / \mathrm{m} 3$ as compared to about $1 \mathrm{~kg} / \mathrm{m} 3$ with conventional explosives. The deflagration speed (VOD)varied from 400 to $800 \mathrm{~m} / \mathrm{s}$ (subsonic) in millionths of a second as compared to detonation speed of 2000 to $6000 \mathrm{~m} / \mathrm{s}$ of emulsion explosives.

d) The borehole pressure islow $\approx 300 \mathrm{MPa}$ as compared to explosives 1500 to $15000 \mathrm{MPa}$ i.e. about $1 / 5$ to $1 / 50$ of conventional explosives.

e) Lower noise and overpressure levels of 55 to $80 \mathrm{~dB}$ as compared to 98 to $+140 \mathrm{~dB}$ with conventional explosives (un-noticed blast). Noise levels depend on degree of muffling and distance from the blast site.

f) Negligible noxious gases.

It is because of above properties that non-explosive pyrotechnic compositions only heave and do not shatter/damage the rock mass (no fly rock) as observed with explosives. Since the borehole pressure is also significantly less and therefore, the vibrations produced are also significantly less (1/10 to1/20)as compared to conventional explosives.

2) Similar yields to small-diameter conventional blasting can be achieved with using smaller charge weights of non-explosive compositions. Primary rock breaking yields around $1 \mathrm{~m} 3$ insitu rock mass per $\mathrm{kg}$ of conventional explosivesagainst only 100 to $150 \mathrm{~g}$ of nonexplosive cartridgeper $\mathrm{m} 3$ insitu rock mass.Significantly greater secondarybreaking yields are produced using non-explosives for breaking boulders.

3) Only localised clearance of 20 to $30 \mathrm{~m}$ for men \& machines are required during blasting with nondetonating pyrotechnics as compared to a minimum of $250 \mathrm{~m}$ with explosives. Production is optimised as no downtime to loading and hauling equipment is experienced due to site evacuation during initiation. Thus, a continuous operation of drilling and blasting can be achieved in parallel to blasting thereby, significantly increasing the production output and reducing production costs.

4) Non-explosive compositions meet the UN $1.4 \mathrm{~S}$ or class $6 / 7$ as per IndianExplosive classification. These classifications are applicable to small arms ammunition and firework and therefore, safer to transport, store and use as compared to conventional explosives where Explosive Act and Regulations are applicable.

5) Non-explosive compositions can be used with low capital, lightweight equipment - One small ROC-203 drill rig or jack hammers are all that is needed to drill the holes up to $100 \mathrm{~mm}$ diameter.

B. Vibrations produced by Non-detonatingPyrotechnic compositions

When the pyrotechnic composition on initiation in a blasthole, deflagrates at low VOD and generates low borehole pressures as compared to explosive, the effect on the blasthole wall is similar to that of rock splitting. Because of significantly low VOD and borehole pressures, the rock mass only heaves and does not shatter resulting in significantly low vibration levels and reduced damage to the surrounding rock mass. However, the magnitude of blast 
induced ground vibration levels on initiation of pyrotechnic composition cartridges in the blasthole depends including:

a) The weight of the pyrotechnic propellant per cartridge or per delay (MCD),

b) The distance between the blasthole and the point of measurement, and

c) The local geological condition of the rock mass and the influence of geology and topography on vibration attenuation

The most common form of vibration equation to predict the amplitude of ground vibration (Vppv) due to nondetonating pyrotechnic compositions at any distance (D) from the 1st row of blasthole has the general form:

$$
\mathrm{Vppv}=\mathrm{K}[\mathrm{D} / \sqrt{ } \mathrm{Q}]^{-\beta}
$$

Where:

$\mathrm{V}=$ Predicted peak particle velocity $(\mathrm{mm} / \mathrm{s})$,

$\mathrm{Q}=$ Maximum quantity of propellant/non-

detonating pyrotechnic composition charge per delay $(\mathrm{kg})$,

$\mathrm{D}=$ Distance from blast shot to sensor $(\mathrm{m})$,

$\mathrm{K}=$ Particle velocity intercept (intercept on the

Particle velocity axis when $\mathrm{D} / \sqrt{\mathrm{Q}}=1$

$(\mathrm{D} / \sqrt{\mathrm{Q}})$ is termed as "scaled distance" $\left(\mathrm{m} / \mathrm{kg}^{1 / 2}\right)$

$\alpha=$ Charge weight component, $=0.5$ and

$\beta=$ Slope factor component (slope of the best fit

line of PPV versus D/ $\sqrt{Q}$ plot on log-logscale. Since the relationship is an inverse linetherefore, the value of $\beta$ is always negativebetween $=-1$ and -2 and is site specific.

It is to be noted that the constant $\mathrm{K}$ in the above equation can be thought to reflect the energy of the propellant per unit mass, and the efficiency with which the energy is transferred to the rock mass. Higher values of $\mathrm{K}$ would be expected with more energetic propellants or in other words $\mathrm{K}$ will be high for explosives or instances where the energy from the propellant is bettercontained within the blasthole. $\mathrm{K}$ varies between $400-700$ for pyrotechnic compositions.

The $\beta$ term is considered to reflect the competency of the rock type between the blasthole and the monitoring location, and the ability of the rock type to transmit vibration. Higher values for $\beta$ (increased attenuation) could be expected in heavily fractured rock types. A typical value for $\beta$ is in the range -1 to -2 with values beyond these limits should be cautiously applied.

A NoneXTM specific vibration equation 2 (Fig.3) has been developed from recorded vibration data's collected from several blasts inBasalt and gneisses (fairrockclass3)using NoneX in sensitive civil applications. These data were collected by an independent group and statistically regressed, according to the distance-D and NoneX weight-Q (MCD), to give the following propagation equation relating PPV, D, and Qmax:

$$
\mathrm{V}_{\mathrm{ppv}}=570\left[\mathrm{D} / \mathrm{Q}^{0.5}\right]^{-1.4}
$$

The PPV vs. Scaled Distance graph in Fig. 3 shows how the peak particle velocity falls away very rapidly as the Scaled Distance is increased.

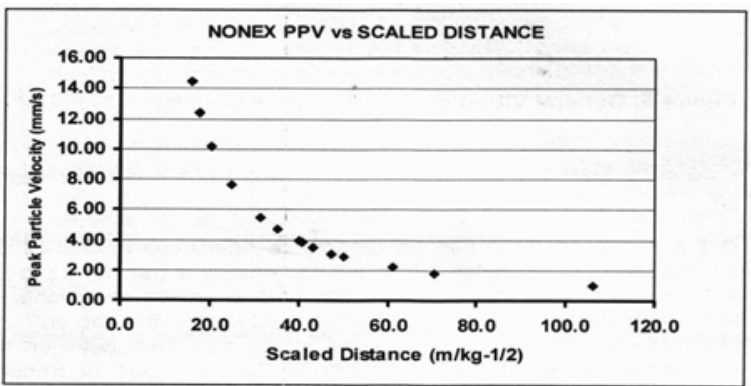

Fig. 3: PPV vs. Scaled Distance for NoneX

With similar rock mass type (fair rock) the site specific propagation equation-3 (Fig.4) was developed fromthe recorded vibration data's of several blasts, using emulsion explosive cartridges,

$$
\mathrm{Vppv}=774[\mathrm{D} / \mathrm{Q} 0.5]-1.49
$$

Based on Table-II permissible limits of PPV a comparison of maximum quantity of NoneX and emulsion explosive charges for various distances is tabulated from eqs. 2 and $3 \&$ listed in Table-III

It may be seen from Table-III that the MCD with NoneX is only 15 percent greater than MCD with emulsion expl. However as mentioned earlier that the charge factor with NoneX is 0.10 to $0.15 \mathrm{~kg} / \mathrm{m} 3$ of rock mass. Thus, for ex. at $10 \mathrm{~m}$ distance one can blast 7 to $11 \mathrm{~m} 3$ of insitu rock with $1.15 \mathrm{~kg}$ of NoneX but can only blast $1 \mathrm{~m} 3$ using only $1 \mathrm{~kg}$ of emulsion explosive to contain the PPV within $25 \mathrm{~mm} / \mathrm{s}$.

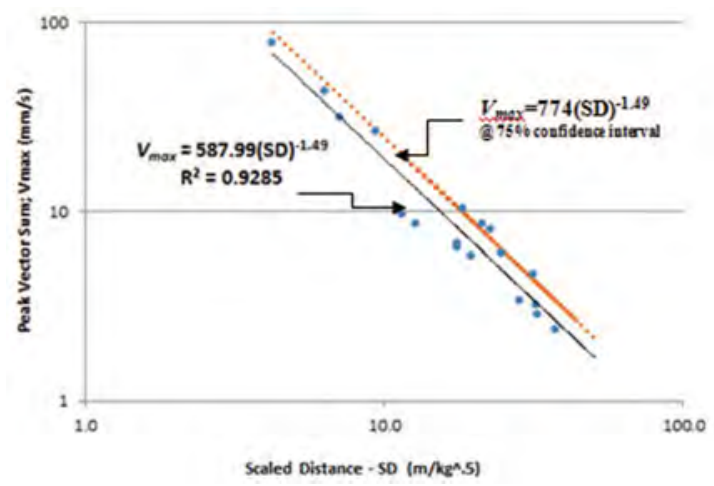

Fig. 4: PPV vs. Scale distance when blasting was done with Emulsion Explosive in fair rock mass.

TABle II: Allowable Limits Of PPV For Different Structures As PER DGMS (1997) CIRCULAR

\begin{tabular}{|l|l|l|l|}
\hline \multirow{2}{*}{ Type of structure } & \multicolumn{3}{|l|}{$\begin{array}{l}\text { Dominant Excitation } \\
\text { Frequency }\end{array}$} \\
\cline { 2 - 4 } & $<8 \mathrm{~Hz}$ & $\begin{array}{l}8-25 \\
\mathrm{~Hz}\end{array}$ & $>25 \mathrm{~Hz}$ \\
\cline { 2 - 4 } & PPV & PPV & PPV \\
\hline \begin{tabular}{l|l|l|}
\hline \multicolumn{2}{|l}{} \\
(A)Building Structures not belonging to the owner
\end{tabular} & 15 \\
\hline $\begin{array}{l}\text { Domestic houses with kuuccha brick and } \\
\text { cement }\end{array}$ & 5 & 10 & 25 \\
\hline RCC Structures & 10 & 20 & 10 \\
\hline $\begin{array}{l}\text { Objects of historical importance \& sensitive } \\
\text { structures }\end{array}$ & 2 & 5 & 25 \\
\hline (B)Building Structures belonging to the mine Owner & 10 & 15 & 50 \\
\hline $\begin{array}{l}\text { Domestic houses with kuuccha brick and } \\
\text { cement }\end{array}$ & 15 & 25 & 5 \\
\hline RCC Structures &
\end{tabular}


It is because of this reason that with emulsion we can't conduct a blast at distance less than say $20 \mathrm{~m}$ using say $4 \mathrm{~kg}$ of explosive/delay which will break about $4 \mathrm{~m} 3$ of insitu rock because the PPV produced at distance less than $20 \mathrm{~m}$ will be more than $25 \mathrm{~mm} / \mathrm{s}$ whereas with NoneX $4 \mathrm{~m} 3$ rock can be fragmented at a distance of only $7 \mathrm{~m}$ from the structure while maintaining the PPV within $25 \mathrm{~mm} / \mathrm{s}$.

The author of this paper conducted few blasts near Jonesburg, South Africa in 2004 for excavation of foundation rock using NoneX to construct a multi-storied building adjoining an already standing 10 storied apartment. MCD was $450 \mathrm{~g}$ and 20 holes were fired in a round using ms electric delay detonators. All persons present were standing only $12 \mathrm{~m}$ away from the blast site. There was absolutely no fly rock, little sound, and vibrations $(10 \mathrm{~mm} / \mathrm{s}$ at about $10 \mathrm{~m}$ distance from the blast site as per vibration records). Mucking of about $70 \mathrm{~m} 3$ blasted rock mass was done using a $0.8 \mathrm{~m} 3$ shovel. The reasons of less ground vibrations can be attributed to deflagration of NoneX (VOD $\approx 600$ to $<800 \mathrm{~m} / \mathrm{s}$ identical to a propellant) which generated small shock waves and slow opening of rock joints by low borehole gas pressures. The resultant effect was absence of flyrock and small sound- attributed to detonators.

TABLE III: PERMISSIBLE NONEX/EXPLOSIVE CHARGE WT. PERDELAY (QMAX-KG) FOR VARIOUS DISTANCES D, AND PPV FROM THE STRUCTURES USING EQUATIONS.-2 \&3.

\begin{tabular}{|l|l|l|l|l|l|}
\hline $\begin{array}{l}\text { S1. } \\
\text { No }\end{array}$ & $\begin{array}{l}\text { Dist. } \\
(\mathrm{D})- \\
\mathrm{m}\end{array}$ & $\begin{array}{l}\text { NoneX MCD= } \\
\text { (kg) for } \mathrm{V}_{\mathrm{ppv}}(\mathrm{mm} / \mathrm{s}) \text {-as } \\
\text { per eq-2. The dominant } \\
\text { frequencies were } \\
\text { between 250-400 Hz }\end{array}$ & $\begin{array}{l}\text { Emulsion } \\
\text { Explos.MCD=Qmax(kg) for } \\
\text { Vppv(mm/s) -as per eq-3. } \\
\text { Dominant frequencies were } \\
50 \text { to100 Hz }\end{array}$ \\
\cline { 3 - 6 } & & $25 \mathrm{~mm} / \mathrm{s}$ & $12 \mathrm{~mm} / \mathrm{s}$ & $25 \mathrm{~mm} / \mathrm{s}$ & $12 \mathrm{~mm}$ \\
\hline 1 & 2.0 & $0.046 \mathrm{~kg}$ & $0.016 \mathrm{~kg}$ & $0.040 \mathrm{~kg}$ & 0.015 \\
\hline 2 & 3.0 & 0.103 & 0.036 & 0.090 & 0.034 \\
\hline 3 & 5.0 & 0.287 & 0.101 & 0.250 & 0.093 \\
\hline 4 & 10.0 & 1.148 & 0.402 & 0.997 & 0.372 \\
\hline 5 & 15.0 & 2.584 & 0.905 & 2.200 & 0.850 \\
\hline 6 & 20.0 & 4.591 & 1.610 & 3.990 & 1.490 \\
\hline 7 & 25.0 & 7.177 & 2.515 & 6.234 & 2.328 \\
\hline 8 & 30.0 & 10.334 & 3.622 & 8.978 & 3.352 \\
\hline 9 & 40.0 & 18.372 & 6.439 & 15.962 & 5.959 \\
\hline 10 & 50.0 & 28.707 & 10.060 & 24.940 & 9.310 \\
\hline
\end{tabular}

It is appropriate to mention that way back in 1887 ; Alfred Noble developed "ballistite" which was a nitroglycerine smokeless powder and a precursor of cordite. Ballistite was the precursor of many modern smokeless powder explosives and still used as a rocket propellant (a mixture of gun powder and nitrocellulose- a VOD of about $<1200 \mathrm{~m} / \mathrm{s}$ ). This is what it is called "non-detonating explosives".

NoneX was used extensively in South African gold mines for ore extraction of narrow gold veins to contain dilution of the blasted ore. It is still the most popular rock breaking product. Since NoneX produces only small magnitude of ground vibrations and therefore, the surrounding rock mass is not fractured. As a result over breaks do not occur and the opening remains stable and requires less supports. Cost of NoneX cartridges is about INR1000 per $\mathrm{kg}$ (unconfirmed). Since the quantity needed is about $1 / 7$ to $1 / 10$ that of emulsions per unit volume of insitu rock mass therefore, overall cost of rock breaking with NoneX is unlikely to be more than say 20 percent that with emulsion explosives (about INR 500/ bcm3). The remaining drilling blasting parameters remain identical in the two systems. It is appropriate to point out that with all the benefits of using pyrotechnic compositions, for ex. NoneX, they are still not tried in India. What is needed is a change of mind-set and attitude, to adopt new technologies which are not only safe, and economicalbut better in performance.

It is anticipated that the efficient use of non-explosive rock breaking techniques will make the concept of "Underground Space Technology" a more viable option in our cities where underground space will demand a premium in short term future. Underground space is an increasing popular option for car parks, and storage places in several highly urbanised areas and these non-explosive methods are one of the most applicable methods to use for excavation in such situations. In most of the developing and developed countries more and more stringent laws and regulations are being enforced with regards to disturbance. Experiments conducted indicated that the energy released on detonation of a $60 \mathrm{~g}$ of NoneX charge was less than $<1 / 10$ th of the energy that is released by a $300 \mathrm{~g}$ charge of 'EMULSION' Explosive when detonated. Fig. 5 illustrates one such study where the PPV from a $60 \mathrm{~g}$ of NoneX, was $1 / 10$ th that produced by $300 \mathrm{~g}$ of explosive thus, enabling rock breaking with safety within a distance of $5 \mathrm{~m}$ from the structure.

When a conventional explosive is detonated it produces shock waves and high levels of vibrations because of high VOD and borehole pressures resulting in crushing and damage to the surrounding rock mass (known as Brisance effect). Several researchers all over the world conducted studies and found a good relationship of the amount of damage to the structure with ground PPV $(\mathrm{mm} / \mathrm{s})$. There is a body of data available, which relates the PPV, as an indicator of the intensity of the vibration level, to the amount of damage inflicted on rock structures by the detonation waves of an explosive. Hoek and Brown (1980) observed the potential damage to tunnels and other rock openings caused by high vibration levels (ppv) as detailed in Table IV.

The damage zone in conventional drilling and blasting in tunnels is suggested by Hoek and Brown as about $3 \mathrm{~m}$ beyond the perimeter of the tunnel surface, depending on the rock mass class, joint numbers, and joint fillings. However, since the propellant based non-explosive compositions do not detonate but deflagrates/burns thereby producing only gases which pressurises the borehole to expand and opens the pre-existing cracks and fractures in the rock mass resulting in heaving the rock mass and not ejecting, as is the case with conventional explosives and therefore do not cause any damage to the surrounding rock mass. It is 
because of this characteristic they are also referred as "rock splitters"

TABLE IV: SUGGESTED DAMAGE LEVELS OF BLAST VIBRATIONS (PPV) FOR UNDERGROUND TUNNELS (AFTER HOEK AND BROWN-1980)

\begin{tabular}{|c|c|}
\hline Form of Damage & $\begin{array}{c}\text { Peak Particle Velocity } \\
(\mathrm{mm} / \mathrm{s})\end{array}$ \\
\hline Breakage of insitu rock mass & $2500 \mathrm{~mm} / \mathrm{s}$ \\
\hline Onset of rock breakage & 650 \\
\hline Rock falls in unlined tunnels & 300 \\
\hline
\end{tabular}

C. Air-Over Pressure/ Noise Levels, \& Flyrock

Overpressure or air blast is simply the pressure over and above that of atmospheric pressure. It is caused by air transmitted vibrations or compression waves. Overpressure levels produced by NoneX are low when compared to conventional explosives and are of shorter duration and less damaging frequency. This is one of the major advantages of NoneX since it produces less psychological effect to the residents particularly in sensitive areas.

Noise is different than overpressure and is measured with a standard sound level meters which record air vibration falling within only audible frequency region. High overpressures are not necessarily audible since the noise levels depend on parameters including type and nature of rock being broken, charge weight per delay, burden and hole confinement. It attenuates with distance but the attenuation can be made faster by covering the exposed detonators, and detonating fuses and muffling the blasting area. In general the noise levels observed with pyrotechnic composition/propellant varies between 55 and $85 \mathrm{~dB}$. In confined spaces belowground the high overpressures associated with detonation of explosive causes 'concussion' which at time is destructive. No such effect is observed with propellants because they burn/deflagrate with controlled gas release and generate low pressure gas pulses thereby restricting the travel distance of the fly rock to within $10 \mathrm{~m}$. However, in actual practise a personnel clearance zone of 20 to $30 \mathrm{~m}$ is normally recommended as a sufficient factor of safety from inadvertent flyrock.

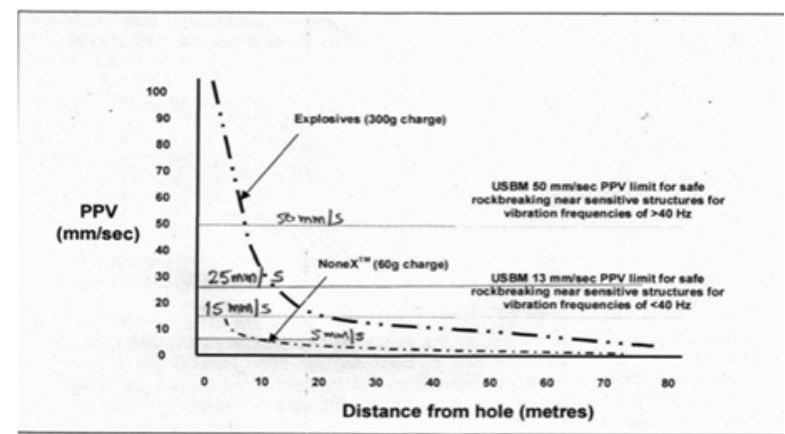

Fig. 5: Typical PPV levels vs. Distance - a comparison of Explosives and NoneX.

\section{IV.STEPS INVOLVED IN ROCKBREAKING PROCESS With NON- \\ DETONATING EXPLOSIVE/ PROPELLANT}

Six easy steps it takes to break the rock mass with nondetonating pyrotechnics/propellant including:

1. Drilled the holes of diameter between $32 \mathrm{~mm}$ (cartg. Dia. $28 \mathrm{~mm}$ ) and $75 \mathrm{~mm}$ (cartg. Dia. $60 \mathrm{~mm}$ )-Table V, as per the required production, at depths up to $3 \mathrm{~m}$, as per blast pattern design,

2. The NoneX Cartridges are placed at the bottom of the drill hole after inserting a detonator in the space provided for the purpose in the cartridge and the electric signal wires from the detonator coming out to the surface. Alternatively, NONEL in- hole shock tube detonator may be used in place of electrical detonators,

3. In cases where production required is more, deeper holes $>3 \mathrm{~m}$ are drilled and they are deck charged by placing stemming between the two cartridges, each cartridge containing a delay detonator (increasing delay period as we go up from the hole bottom),

Stem the remaining top portion of the hole by granular crushed rock and firmly tamped

4. The signal wires or the shock tubes of all the charged holes are hooked-up as per the designed blasting pattern; the circuit continuity is checked,

5. The blast holes are covered with sand filled gunny bags or steel 'Hole Iron 'followed by covering of the entire area to be blasted by blast mates followed by covering the blast mats with 'light coverage mats' if required for extra safety,

6. Once all the holes are charged, stemmed, hooked-up and covered/muffled the area is cleared for a distance of at least $20-30 \mathrm{~m}$ and guards are posted to prevent inadvertent access,

7. Laudable Signals are sounded using an electrical siren to indicate the intention of blasting by alarm, alert and Fire signals,

8. The firing cable is connected to the exploder, the exploder is charged and the firing button is pressed from a safe position.

TABLE V: NONEXTM CARTRIDGE SIZES (WITH INBUILT DETONATOR OR STANDALONE STATE)

\begin{tabular}{|c|c|c|}
\hline $\begin{array}{c}\text { Cartridge dia. } \\
\mathrm{mm})\end{array}$ & Hole Dia. (mm) & $\begin{array}{c}\text { NoneX charge Weight } \\
\text { (g) }\end{array}$ \\
\hline 28 & 30 to $34 \mathrm{~mm}$ & 20 to $120 \mathrm{~g}$ \\
\hline 34 & 36 to $42 \mathrm{~mm}$ & 20 to $180 \mathrm{~g}$ \\
\hline 60 & 64 to $76 \mathrm{~mm}$ & 200 to $600 \mathrm{~g}$ \\
\hline
\end{tabular}

A. Accessories with the blasting system

The main accessories which are required during blasting include:

1. Electric delay detonators or for larger blast NONEL system with shock tube TLD and In-hole delay detonators. The hook-ups with non-detonating explosives are identical to conventional blasting hookups

2. Ignition Blast Cable with reel $=50 \mathrm{~m} \times 2$ with wire crosssection $=1.5 \mathrm{~mm}^{2}$

3. Exploder suitable for +100 shot of electric detonators, each detonator of 1.8 to $2 \mathrm{ohms}$ and with 2.5 to $6.5 \mathrm{~m}$ signal wire of $1.8 \mathrm{ohms}$ resistance, Ignition current 3.5 Amp., Ignition time <2ms @3.5A, Measure current 0.5 Amp.

4. DGMS approvedBlasting circuit continuity tester

5. Sequential Blasting machine (optional) 
6. Hole Iron (optional)suitable for blasthole diameter to cover the blasthole mouth and to contain the stemming material ejection (optional)

7. Light Coverage heavy cloth in sizes of $5 \mathrm{~m} \times 5 \mathrm{~m}$ or more. The entire blast area must be covered as a precautionary measure,

8. Blast mats of heavy weight in sizes of $3 \mathrm{~m} \times 4 \mathrm{~m}(900 \mathrm{~kg}$ wt.); $3 \mathrm{~m} \times 5 \mathrm{~m}$ (1150 kg wt.); $3 \mathrm{~m}$ x6m (1350 kg wt.) may be used but(optional),

9. Atlas Copco Rock Drilling Equipment for ex. Rock drilling machine Model: ROC-203; RH 572 E or RH 658 L,

10. Drill rods for ex $22 \mathrm{~mm}$ to $38 \mathrm{~mm}$ dia. Or more $(60 \mathrm{~mm})$ compatible with the drill bit diameter of various standard lengths say for ex. 0.6, 1.2, 1.5, 1.8, 2.4, 3.0, 4.0; 5.0, $6.0 \mathrm{~m}$.

11. Electric Siren or Hooter to give waning signals pre and post blastingoperation,

12. Red flags and danger signal posters installed in the danger zone all around the blasting area plus $30 \mathrm{~m}$ from the blast site,

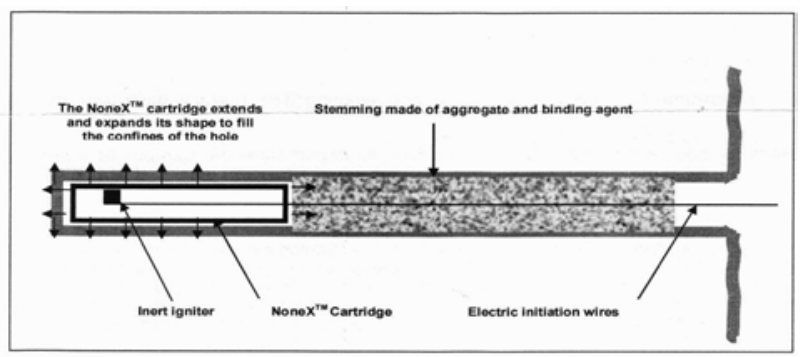

Fig. 6: General Arrangement of inserting non-Explosive cartridge in a blasthole

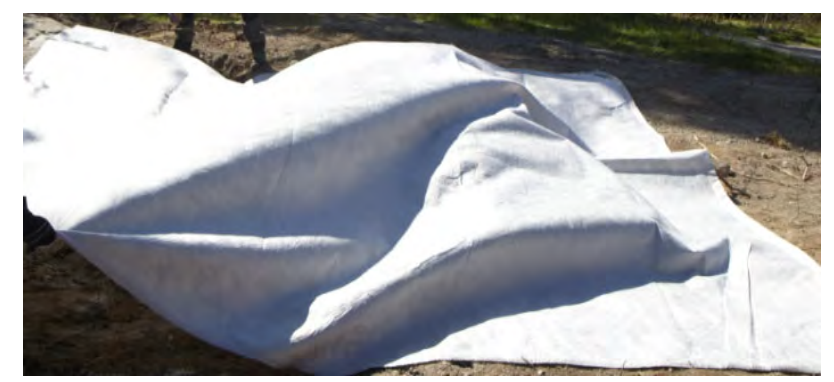

Fig.7: Light coverage mats to prevent dust and fly rock from escaping and becoming air born.

\section{V.Rock Fragmentation By PUlse Plasma System OF KAPRA}

The Korea Accelerator and Plasma Research Association (KAPRA) have developed a system called "EPI Pulse Plasma" rock fragmentation system. It consists of two parts1) EPI (Electro Power Impactor) Method and 2) Reaction Cell.

In this system when high voltage and current electric pulse (electric energy) generated by an EPI is supplied to the cells filled with powders of Aluminium and copper Oxide for a milli-seconds, then the cells electrolyte converts into plasma state generating impact energy due to thermic reaction, resulting in generation of high heat and impact wave (pulse) which causes the rock to disintegrate with weak noise and vibration.After the reaction, only solid materials, i.e. aluminium oxide and copper remains but in the process it generates low noise, low vibration, and low dust and little flyrock. The whole process is completed in milli-seconds and therefore, the duration of vibration is small since the energy dissipation is very fast thus, attenuates within very short distance.

In conventional rock blasting when explosives are detonated seismic waves are generated and the explosive chemicals convert to gases. This detonation process is slow (takes several milli-seconds to complete) and multiple shock waves are generated due to delays and travel long distances. As a result significant noise and vibrations are generated and the borehole pressure causes the flyrock. On the contrary with Plasma blasting the ground frequencies with EPI system is high $(50-120 \mathrm{~Hz})$ as compared to blasting with explosives $(15-30 \mathrm{~Hz})$ results in resonance since the natural frequencies of buildings are typically $15-20 \mathrm{~Hz}$.

In EPI system no toxic fumes are generated, and therefore, it does not disturb any other operation nearby. It can be used in weak to hard rock mass. In one round up to 7 nos. of holes can be exploded even in watery strata. Figs. 8 and 9 illustrate the overall concept of Pulse Plasma System of rock breakage. The hole diameter typically is $51 \mathrm{~mm}$, with hole depths up to $2.5 \mathrm{~m}$, burden about $0.8 \mathrm{~m}$ and holes spacing is maximum 0.9 to $1.3 \mathrm{~m}$.

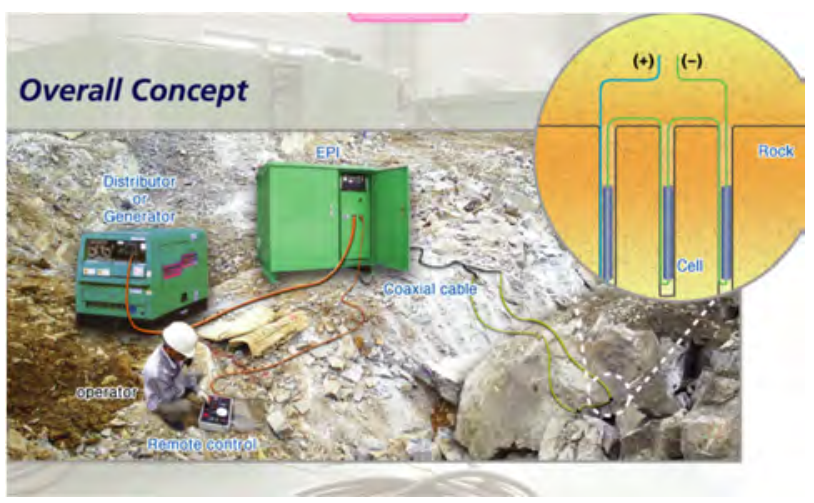

Fig. 8: Overall concept of Plasma Blasting-KAPRA

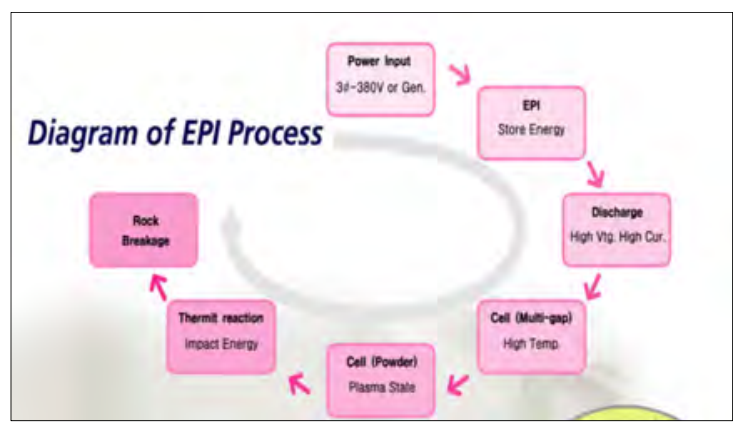

Fig.9: Flow chart of a rock fragmentationProcess using Plasma Blasting

Reaction of the Cell: The reaction cell contains an electrolyte which is a mixture of Aluminium and Copper Oxide in powder form. A pair of electrodes is inserted in the cell which converts the powder into plasma state when high power pulse electric energy is supplied. The chemical reaction is as follows: 


$$
2 \mathrm{Al}+3 \mathrm{CuO} \rightarrow \mathrm{Al}_{2} \mathrm{O}_{3}+3 \mathrm{Cu}+1197 \mathrm{~kJ}
$$

The dimension of the reaction cells varies from $600 \mathrm{~mm}$ to $1000 \mathrm{~mm}$ length, weight from $925 \mathrm{~g}$ to $1542 \mathrm{~g}$, releasing energy from 3784 to $6308 \mathrm{~kJ}$ respectively. A typical cell is of $34 \mathrm{~mm}$ diameter for drill hole diameter of $51 \mathrm{~mm}$. The drill hole pattern varies from $1 \mathrm{~m} \times 1 \mathrm{~m} \times 2.4 \mathrm{~m}$ to $1.3 \mathrm{~m} \times 1.3 \mathrm{~m} \mathrm{x}$ $3.0 \mathrm{~m}$ (depth). The charge factor is typically $3 \mathrm{~m} 3$ per $\mathrm{kg}$ of cell weight. Trials indicated that the ground vibrations generated with Plasma Blasting varied from $1 / 12$ to $1 / 20$ and the sound levels varied from $1 / 6$ to $1 / 36$ that of a typical blasting with explosives for the same scale distance. The method is most suitable for pre-splitting and secondary blasting of boulders.

\section{VI.CONCLUSIONS}

Most of the rocks are fragmented mainly by two methods including

1) Chemical mixtures including

a) Drilling and blasting using explosives whichdetonates $(\mathrm{VOD}+2000 \mathrm{~m} / \mathrm{s})$, and

b) Drilling and blasting using non- detonating explosives i.e. pyrotechnic compositions/ propellants which deflagrate (VOD- $400-1000 \mathrm{~m} / \mathrm{s}$ ) but do not detonate,

c) Recently, the Korea Accelerator and Plasma Research Association (KAPRA) have developed a system called "EPI Pulse Plasma" rock fragmentation system confined to South Korea.

2) Mechanical including Rippers, Rotary Drum Cutters, Splitters and Surface Miners.

- Rock excavation in highly populated areas and in cities where multi storied structures are being built for ex. METRO Stations the conventional blasting with explosives, including controlled blasting techniques, are invariably used to contain the blast induced vibrations, flyrock, and sound within the permissible limits. However, due to restrictions of MCD higher productions greater than say 100-150 m3/day are difficult to achieve. Blasting with conventional explosives has led to public outcry and court cases thereby, delaying the construction period and resulting in cost over-runs.

- Non-detonating Pyrotechnic compositions/ propellants are being increasingly used in such situations. These are not manufactured in India so far mainly because of no demand due to ignorance of the of the practicing mining, construction and infrastructure engineers.

- It is concluded that within the stipulated permissible blast induced ground vibrations, air overpressures, and fly the non-detonating pyrotechnic compositions for ex. NoneX can be safely used for excavation in all class of rocks in the vicinity of several important surface structures located within as close as $3 \mathrm{~m}$ of the excavation boundaries and productions of 500 to 1000 $\mathrm{m} 3$ /day These are non-detonating and falls under UN classification $1.4 \mathrm{~S}$, UN No. 0432 for transportation, handling and use. It is a deflagrating type of explosives (class-6/7 as per PESO- India and can be used with either an electrical or Non-electrical detonators initiation system. This product produces very low level of vibration (1/10 when compared to explosives), little fly rock (max. distance less than $10 \mathrm{~m}$, and little sound,

- The charge factor of Pyrotechnic compositions is only $100-150 \mathrm{~g} / \mathrm{m} 3$ of rock as compared to $1 \mathrm{~kg} / \mathrm{m} 3$ of conventional explosives. It is estimated that increase in overall excavation cost per $\mathrm{m} 3$ of excavated will be only 20 percent to that of excavation with conventional explosives.

- It has the flexibility of conducting unlimited number of blasting rounds any time of the day without evacuating the men and machineries contrary to conventional blasting with explosive since it does not come under the category of conventional detonating explosives.

- Plasma blasting technique is a recent development which also produces low level of vibrations with little sound and no flyrock. However, the detailed cost analysis per unit volume of rock excavated is missing and as such not popular.

\section{REFERENCES}

[1] Catalogues and brochures of NXCO Mining Technologies, Ltd, South Africa,

[2] Catalogues and brochures of KAPRA (KoreaAccelerator and Plasma Research Association

[3] R.N. Gupta and A.K. Raina, "Controlled blasting for a new tunnel near an existing railway tunnel, Thane" International Conference on Rock Fragmentation by blasting, 2012, New Delhi, India. 